\title{
PRESERVAÇÃO DA QUALIDADE PÓS-COLHEITA DA CARAMBOLA COMSOLUÇÃO FILMOGÊNICA DE QUITOSANA
}

Alex Guimarães Sanches, Maryelle Barros da Silva, Elaine Gleice Silva Moreira, Carlos Alberto Martins Cordeiro

Universidade Federal do Pará - UFPA. E-mail: alexsanches.eng@gmail.com

\section{RESUMO}

A fisiologia pós-colheita da carambola é marcada por uma série de transformações fisiológicas e bioquímicas que favorecem a perda de qualidade do frutoao longo doperíodo de armazenamento, podendo-se destacar a elevada perda de água, o amolecimento da polpa, a perda de coloração natural, dentre outros. Com o intuito de minimizar esses efeitos o presente trabalho teve por objetivo avaliar diferentes concentrações de quitosana como revestimento na preservação dos constituintes físico-químicos durante o armazenamento refrigerado de carambolas. $O$ experimento foi conduzido em delineamento inteiramente casualizado sob arranjofatorial $4 \times 5$, isto é, quatro concentrações de quitosana (0, 1, 2 e 3\%) e cinco tempos de armazenamento (0, 4, 8, 12 e 16 dias). Em intervalos de quatro dias determinou-se: perda de massa fresca, firmeza dos frutos, coloração da casca $\left(H^{\circ}\right.$ e C), sólidos solúveis totais, acidez titulável, relação SS/AT, pH econteúdo de vitamina $\mathrm{C}$ total. O revestimento com 2 e $3 \%$ de quitosana resultaram em frutos mais firmes, com menor perda de massa, da coloração natural e do conteúdo de vitamina $C$ total, além de não promover alterações quanto ao sabor através do conteúdo de sólidos solúveis, acidez titulável e pH.

Palavras-chave: Averrhoa carambola L.; atmosfera modificada; revestimento.

\section{PRESERVATION OF POST-HARVEST QUALITY OF STAR FRUIT COATED WITH CHITOSAN SOLUTION}

\begin{abstract}
The post-harvest physiology of the carambola is marked by a series of physiological and biochemical transformations that favor the loss of fruit quality during the storage period, being it possible to highlight the high loss of water, the softening of the pulp, the loss of natural coloration, among others. In order to minimize these effects, the present work aimed to evaluate different concentrations of chitosan as a coating in the preservation of physicochemical constituents during refrigerated storage of carambolas. The experiment was conducted in a completely randomized design under a $4 \times 5$ factorial arrangement, that is, four concentrations of chitosan (0, 1, 2 e 3\%) and five storage times $(0,4,8,12$ and 16 days). At four-day intervals, fresh weight loss, fruit firmness, peel color $\left(\mathrm{H}^{\circ}\right.$ and $\left.\mathrm{C}\right)$, total soluble solids, titratable acidity, SS / AT ratio, $\mathrm{pH}$ and total vitamin $\mathrm{C}$ content were determined. The 2 and $3 \%$ chitosan coating resulted in firmer fruits with lower mass loss, natural coloring and total vitamin $\mathrm{C}$ content, and did not promote flavor changes through the content of soluble solids, titratable acidity and $\mathrm{pH}$.
\end{abstract}

Key words: Averrhoa carambola L.; modified atmosphere; coating.

\section{INTRODUÇÃO}

A caramboleira (Averrhoa carambola L.) é uma fruteira tropical do Sudeste asiático, cultivada na Malásia, sul da China, Taiwan e Índia, sendo relativamente popular nas Filipinas, Austrália e em algumas ilhas do Pacífico Sul (DONADIO et al., 2001). O Brasil é um dos maiores produtores de carambola do mundo, sendo grande parte da produção proveniente de pequenos pomares, localizados em sua maioria no Estado de São Paulo (NATALE et al., 2008).

A carambola é um fruto atrativo pelo seu formato de estrela, quando cortado em fatias transversais, com casca translúcida e brilhante, 
polpa amarela de tonalidade intensa e sabor agridoce (NEVES et al., 2004). A polpa também utilizada para preparar geleias, molhos, compotas e picles, se enquadrando na categoria de alimentos funcionaisounutracêuticos, uma vez que é rico em compostos químicos importantes à saúde humana (SHUI; LEONG, 2006).

Os frutos da caramboleiraatingem a maturidade fisiológica quando ainda estão ligados à árvore (NEVES et al., 2004) e após a colheita são observadas muitas reações químicas, que culminam também em alteraçõesfísicas, dentre as quais se destacam, para este fruto em particular, a excessiva perda de água,o amolecimento da polpae o ressecamento, ocasionados pela transpiração e armazenamento inadequado (SEPIAH-PLOETZ; COOKE, 2003) necessitando, portanto, de tecnologias de conservação adequadas para minimizar esses efeitos.

Assim, o uso de revestimentos à base de compostos naturais ou biodegradáveis, não tóxicos, derivados de animais ou plantas, tem-se destacado nos trabalhos de conservação de produtos vegetais (BAUTISTA-BAÑOS et al., 2006), sendo a quitosana um desses produtos.

A quitosana é um polissacarídeo obtido da desacetilização da quitina, presente principalmente em insetos e invertebrados marinhos, com ação fungistática sem, porém, causar toxidade ao organismo humano (BERGER et al., 2011). Quando dissolvida em meio ácido e aplicada sobre a superfície dos frutos forma uma membrana semipermeável que tem sido amplamente utilizada na proteção de frutos perecíveis contra a desidratação, redução da respiração, manutenção da firmeza e coloração (ALI et al., 2011).

Além de minimizar as alterações ocasionadas pela pós-colheita de frutas e hortaliças, a quitosana vem sendo amplamente utilizada por se tratarde um produto natural oriundo de resíduos de processamento, de baixo custo de obtenção, biodegradávele abundante na natureza (FREDDO et al., 2014).

Nesse contexto, o presente trabalho tem por objetivo avaliar diferentes concentrações de quitosana como revestimento na preservação da qualidade pós-colheita de carambolas durante 0 armazenamento refrigerado.

\section{MATERIAL E MÉTODOS}

Frutos de caramboleiras da cultivar Nota 10 , foram colhidas no estádio 3 de maturação fisiológica, isto é, com coloração completamente amarela. A colheita dos frutos foi realizada em plantas com idade de 7 anos localizadas em propriedade agrícola familiar situada sob as coordenadasgeográficas (52 16' 42,19" W e 3은 10 ' 0,82" S), município de Altamira-Pará.

Após a colheita e lavagem dos frutos no packing house da própria unidade de produção, os mesmos foram transportados à temperatura de 14 ํ por cerca de $30 \mathrm{~min}$ até a unidade do Centro de Estudos Ambientais - CEA, Laboratório de Biotecnologia Aplicada situado no município de Altamira-Pará.No laboratório, os frutos foram sanitizados em solução contendo hipoclorito de sódio a $150 \mathrm{mg} . \mathrm{L}^{-1}$ por $5 \mathrm{~min}$, seguido de lavagem em água deionizada. Após a sanitização, os frutos foram dispostos em bancadas para a secagem com auxílio de papel toalha.

Após secos, os frutos foram submetidos aos tratamentos contendo quitosana. Para o preparo da solução foi utilizada quitosana (SigmaAldrich, USA) de peso molecular médio, com pureza de $99,5 \%$ e $75-85 \%$ de desacetilação. Foram preparadas soluções de quitosana nas concentrações de $0 \%$ (controle), $1 \%, 2 \%$ e $3 \%$ $(\mathrm{p} / \mathrm{v})$ contendo $0,5 \mathrm{~mL}(\mathrm{v} / \mathrm{v})$ de ácido acético glacial. A solução foi agitada durante $12 \mathrm{~h}$, sendo controlado o pH na faixa de 5,6 - 5,8 com o próprio ácido acético glacial.

Após as soluções preparadas, os frutos foram imersos por $1 \mathrm{~min}$ e em seguida retirados para o escorrimento do excesso de solução por $30 \mathrm{~s}$. Em seguida estes foram acondicionados em bandejas de isopor de poliestireno revestida com filme plástico de PVC 14 micras e armazenados em refrigerador a $10 \pm 2^{\circ} \mathrm{C}$ e85 $\pm 5 \%$ de U.R.

$\mathrm{O}$ ensaio foi conduzido em esquema fatorial $(4 \times 5)$ em delineamento inteiramente casualizado, sendo os fatores quatro concentrações de quitosana: 0,0 (controle), 1,0, 2,0 e 3,0\% e cinco dias de avaliação: 0, 4, 8, 12 e 16 dias após aplicação dos tratamentos com quatro repetições e a parcela experimental composta por quatro carambolas.

As análises físico-químicas e sensoriais foram determinadas logo após a aplicação dos tratamentos (tempo zero) e a cada quatro dias em um total de 16 dias de ensaio, de acordo com as metodologias descritas a seguir:

A perda de massa fresca foi obtida a partir da diferença no peso das bandejas contendo quatro frutos no dia zero e a cada dia de avaliação. Foi utilizada uma balança semianalitica digital (Bioprecisa, modelo BS3000A) e 
os resultados foram expressos em percentagem (\%).

A firmeza foi medida na região mediana nos quatro frutos inteiros de cada repetição, utilizando-se um texturomêtro (modelo FT 327, Stevens LFRA Texture Analyser) com ponta de prova A 9/1000, velocidade de penetração de 2,0 $\mathrm{mm} \mathrm{seg}^{-1}$ e profundidade de $5 \mathrm{~mm}$. Os resultados foram expressos em Newtons (N).

A coloração da casca dos frutos foi determinada utilizando um colorímetro portátil (modelo CR-300, Minolta). Foram realizadas três leituras em pontos equidistantes na região equatorial dos frutos, compondo um valor médio para os parâmetros: ângulos Hue $(H)$ e Chroma (C).

O teor de sólidos solúveis foi determinado a partir da extração de duas gotas de suco de uma amostra da polpa na região mediana dos frutos. O suco foi extraído por prensa manual e depositado diretamente sobre o prisma de um refratômetro digital (modelo PR 201, ATAGO) e os resultados expressos em ㅇ Brix.

A acidez titulável foi determinada por titulometria seguindo a metodologia descrita pela AOAC (2012). Foram retirados $10 \mathrm{~g}$ da polpa de carambola que adicionado a $50 \mathrm{~mL}$ de água destilada foram homogeneizados e titulados em solução com $\mathrm{NaOHa} 0,1 \mathrm{~N}$ e fenolftaleína a $1 \%$ como indicador do ponto de viragem, utilizando bureta digital e os resultados expressos em \% de ácido oxálico. $100 \mathrm{~g}^{-1}$ de massa fresca MF.

$O$ ratio SS/AT determinado pelo equilíbrio entre doce-ácido do produto durante o amadurecimento do fruto, foi calculada pela diferença entre sólidos solúveis e a acidez titulável (SS/AT).

$\mathrm{O} \mathrm{pH}$ das amostras foi determinado por potenciometria utilizando-se um potenciômetro (ANALYSER, modelo $\mathrm{pH} 300$ ), conforme técnica descrita por AOAC (2012).

O conteúdo de vitamina C total foi determinado pelo método proposto por Chen e Wang (2002) em espectrofotômetro a 525 nm, sendo os resultados expressos em $\mathrm{g}$ de ácido ascórbico por $100 \mathrm{~g}^{-1}$ de massa fresca (MF) com base em uma curva de calibração.

Os dados de cada análise foram submetidos aos testes de normalidade e homogeneidade (Shapiro-Wilk). Não havendo restrições, os dados foram submetidos à ANOVA $(p \leq 0,05)$ e as médias comparadas pelo teste de Tukey $(p \leq 0,05)$, seguidos de análise de regressão com auxílio do programaAssistat7.7 versão beta (SILVA; AZEVEDO, 2016).

\section{RESULTADOS E DISCUSSÃO}

Ao longo do período de armazenamento houve redução na massa fresca dos frutos em todos os tratamentos (Figura 1).

Figura1. Perda de massa fresca (\%) em carambolas submetidas a diferentes concentrações de quitosana ao longo de 16 dias de armazenamento refrigerado a $10 \pm 2^{\circ} \mathrm{C}$.

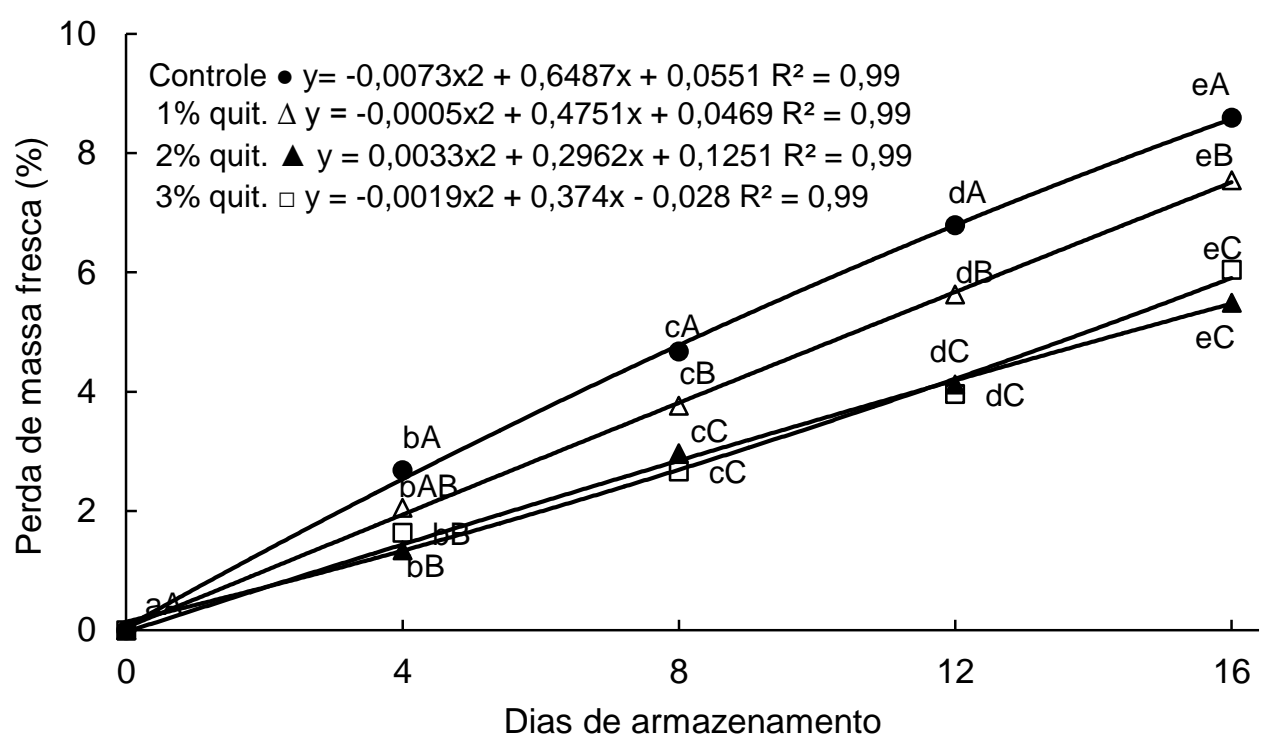

A maior perda de massa é evidenciada nos frutos do tratamento controle com redução de até $8,59 \%$ ao final de 16 dias de armazenamento. Nos frutos revestidos com quitosana, nota-se maior restrição na perda de água, influenciado possivelmente pela barreira 
física criada pelo revestimento sob a epiderme dos frutos, reduzindo com isso as trocas gasosas, especialmente quando tratados com 2 e 3\%, cujas médias corresponderam a 5,89\% e 5,49\%, para o mesmo período, respectivamente.

De modo similar, Ali et al. (2011) e Velickova et al. (2013), também verificaram que o aumento na concentração de quitosana restringiu a perda de massa fresca em mamões da cv. Eksotika e em morangos, respectivamente, sugerindo que a espessura do revestimento pode limitar ou não a perda de água para o ambiente, durante os processos de respiração e transpiração dos frutos.

A firmeza das carambolas reduziu com o tempo de armazenamento em todos os tratamentos avaliados. Em geral, os valores médios passaram de $22,06 \mathrm{~N}$ no dia zero para $6,78 \mathrm{~N}$ ao final de 16dias (Figura 2).

Figura 2. Firmeza $(\mathrm{N})$ em carambolas submetidas a diferentes concentrações de quitosana ao longo de 16 dias de armazenamento refrigerado a $10 \pm 2^{\circ} \mathrm{C}$.

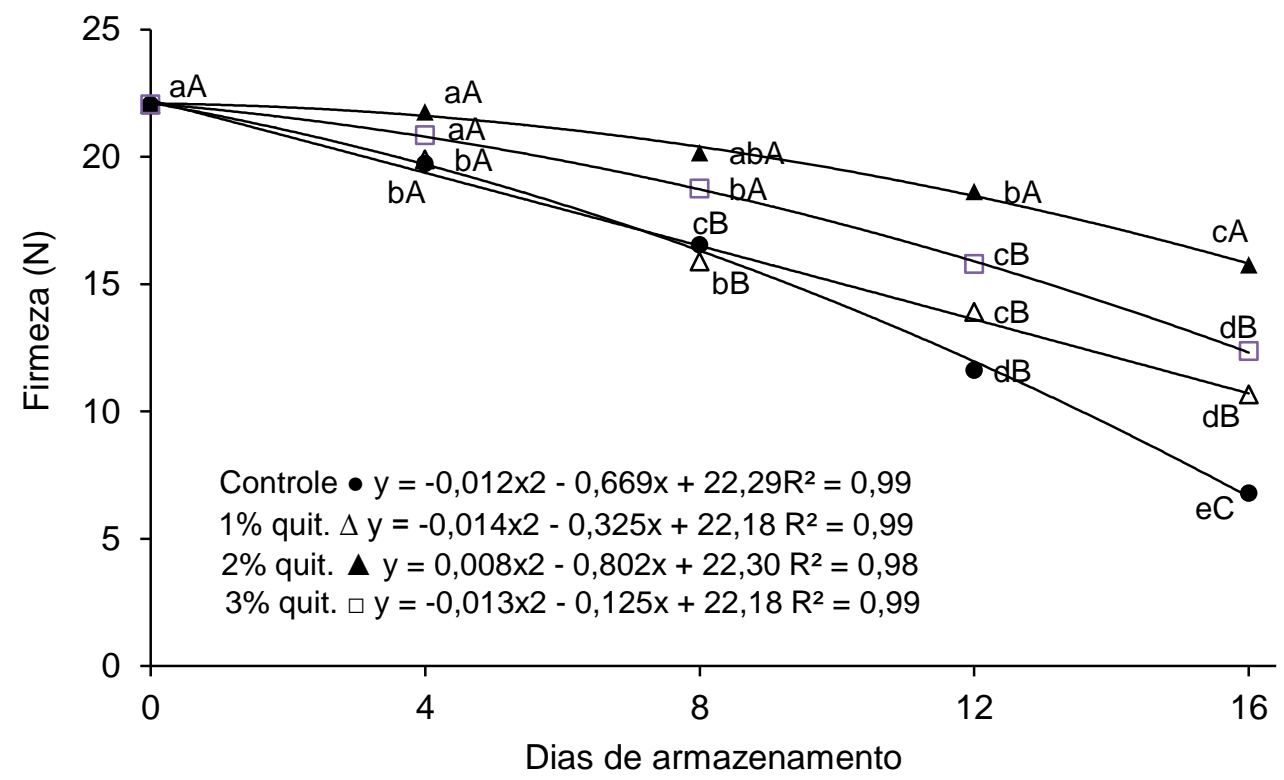

Segundo Jacomino et al. (2002), uma das principais causas da redução na firmeza de polpa de carambola está relacionadaà degradação da lamela média, aumentandoa quantidade depectina solúvel e perda de açúcares neutros não-celulósicos que se tornam mais evidentes como avanço no estádio de amadurecimento.

Avaliando a relação entre os tratamentos é possível notar que não houve diferença estatística $(p<0,05)$ entreeles até o segundo dia de avaliação quando os tratamentos controle e quitosana a $1 \%$ apresentaram reduções mais expressivas na firmeza dos frutos. A concentração de quitosana a $2 \%$ por sua vez promoveu maior firmeza aos frutos quando comparados com os demais tratamentos, durante os 16 dias de avaliação com redução de apenas $6 \mathrm{~N}$ em relação ao tempo zero (Figura 2). Oliveira et al. (2015) também verificaram redução na firmezade carambolas armazenadas em embalagens de polipropileno $(8,4 \mathrm{~N})$ e filme plástico de PVC $(6,5$ $\mathrm{N})$ durante 21 dias de armazenamento a $3 \stackrel{\circ}{ } \mathrm{C}$.
É possível notar que ao fim do período de armazenamento a maior concentração de quitosana (3\%) não promoveu resistência aos frutos (Figura 2), provavelmente, devido à excessiva restrição às trocas gasosas entre os tecidos das carambolas e a atmosfera externa.

Diferentemente dos nossos resultados, Cerqueira et al. (2011) avaliando goiabas e Galo et al. (2014) com mamões da cultivar "Sunrise solo" observaram que as maiores concentrações quitosana ( $6 \%$ e $1,25 \%$ ), respectivamente, foram mais eficientes em reduzir a degradação das pectinas que compõem a parede celular dos frutos, mantendo, desta forma, maior firmeza dos tecidos.

O ângulo Hue é indicativo de tonalidade com medidas que variam do amarelo ao

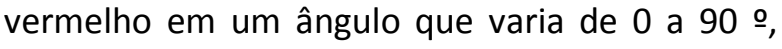
assim,quanto maior este for, mais amarelo é o fruto, e, quanto menor for, mais vermelho é o fruto. Analisando a Figura 3 observa-se que houve redução nos valores médiosem todos os 
tratamentos ao longo doperíodo de armazenamento.

Figura 3. Ângulo hue (ㅇ) em carambolas submetidas a diferentes concentrações de quitosana ao longo de 16 dias de armazenamento refrigerado a $10 \pm 2{ }^{\circ} \mathrm{C}$.

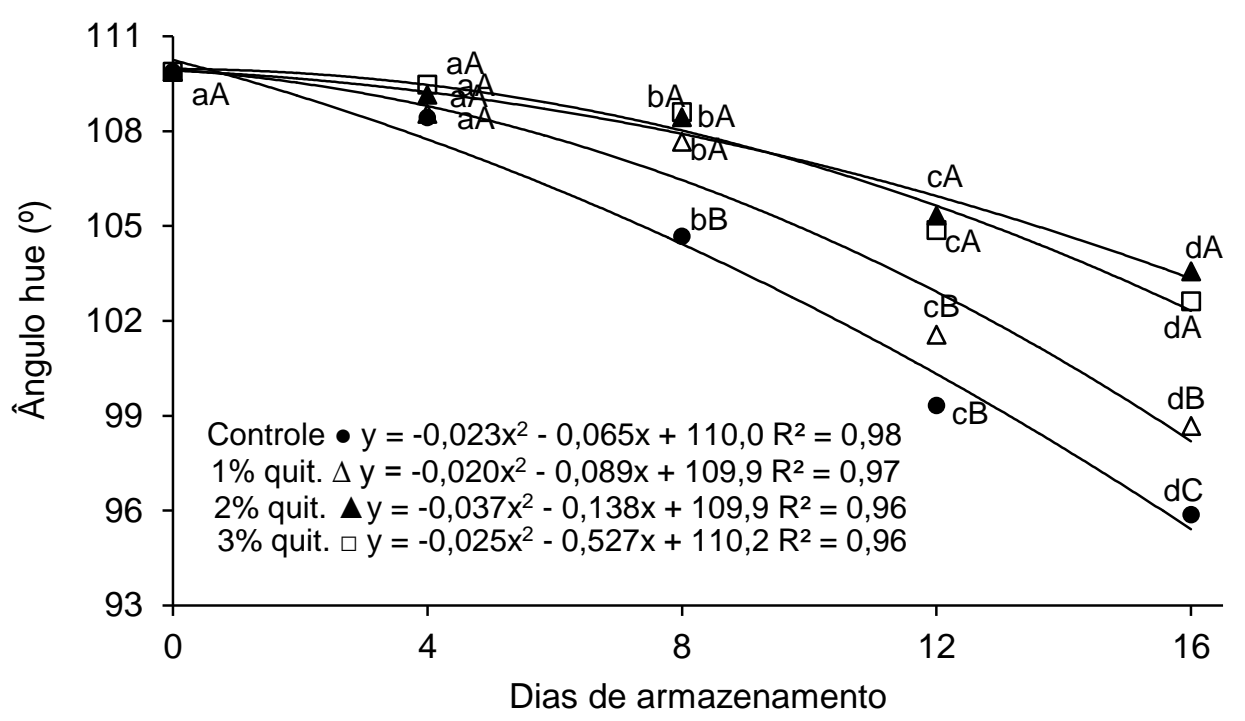

Essa redução nos valores mostra que houve perda da coloração característica do fruto maduro (amarelo) com o tempo de armazenamento sendo, portanto, um indicativo de senescência através da através da presença de cores como o laranjado e o vermelho nos frutos.

Dinget al. (2007) também observaram redução nos valores de ângulo hue em carambolas da cv. B10 minimamente processadas ao longo de 5 dias de armazenamento a 7 ㅇ․

No que se refere aos tratamentos, observa-se efeito significativo $(p>0,05)$ especialmente após o quarto dia de armazenamento quando os frutos do tratamento controle apresentam um declínio mais acentuado nos valores de ângulo hue com média de 95,87 ao final de 16 dias (Figura 3). Tal fato permite inferir na potencialidade evidenciada pelo uso da quitosana na manutençãoda coloração amarelodos frutos por maiortempo, sugerindoum retardo no processo de senescência através do bloqueio favorecido pelo revestimento, especialmente nas concentrações de 2 e $3 \%$.

O chroma ( $C$ o) define a intensidade de cor, assim, quanto maior o valor, mais intenso é a cor amareloem decorrência da senescência. De modo geral, os valores de chromaaumentaram amedida que houve avanço nos dias de armazenamento das carambolas em todos os tratamentos (Figura 4).

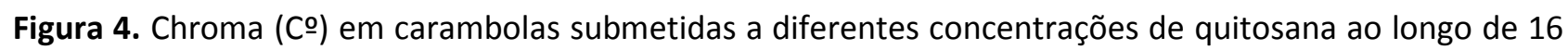
dias de armazenamento refrigerado a $10 \pm 2{ }^{\circ} \mathrm{C}$.

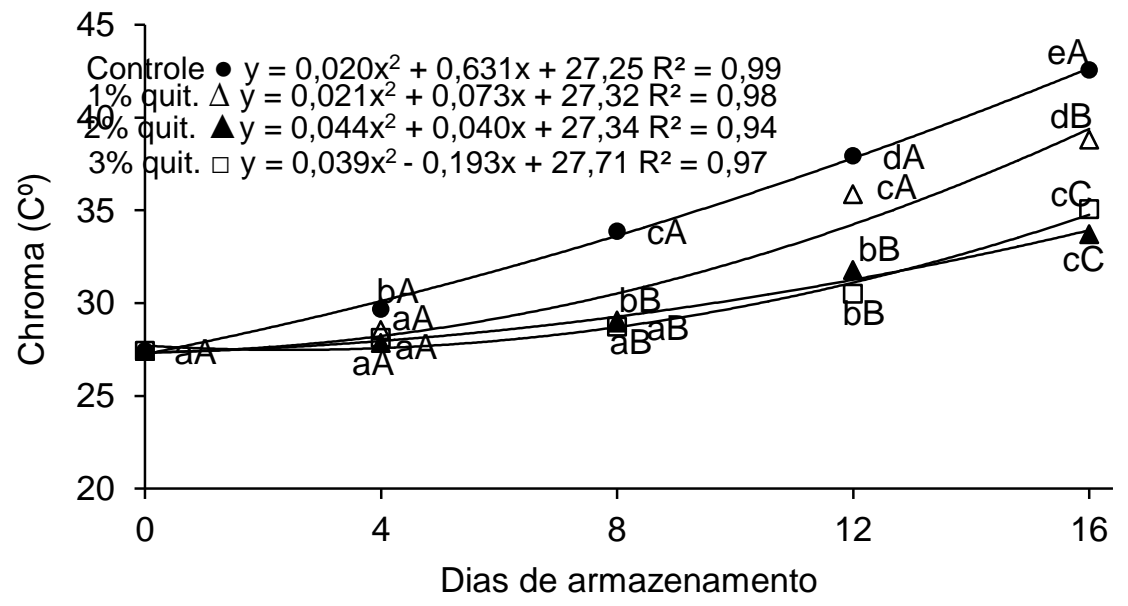


Em relação ao tempo de armazenamento, só houve diferença significativa $(p>0,05)$ entre os tratamentos a partir do oitavo dia, observando maiores valores de chroma nos frutos controle e quando revestidos com quitosana $1 \%$ ao final de 16 dias (Figura 4).

Para o mesmo período (16 dias), carambolas tratadas com quitosana 2 e $3 \%$ não diferiram entre si $(p<0,05)$, indicando que 0 revestimento agiu atenuando astrocas gasosas com o meio externo, retardando assim, a síntese de pigmentos e a senescência através da preservação da cor natural dos frutos (Figura 4).

De modo similar, concentrações maiores de quitosana $(0,5 \%)$ utilizada em lichias (HOJO et al., 2011) e $1 \%$ em bananas (HOSSAIN; IQBAL, 2016) também preservaram a cor natural desses frutos em relação ao controle sugerindo que a barreira física gerada pelo filme reduziu os processos metabólicos decorrentes do amadurecimento.

O conteúdo de sólidos solúveis totais (SST) apresentou variações ao longo do tempo de armazenamento. Nos frutos revestidos com 2 e $3 \%$ de quitosana observou-se um aumento linear de SS ao longo dos 16 dias, no entanto, nos tratamentos controle e quando revestidos com $1 \%$ de quitosana nota-se redução nos valores médios após o $12^{\circ}$ dia de análise (Figura 5 ).

Figura 5. Sólidos solúveis totais (Brix) em carambolas submetidas a diferentes concentrações de quitosana ao longo de 16 dias de armazenamento refrigerado a $10 \pm 2{ }^{\circ} \mathrm{C}$.

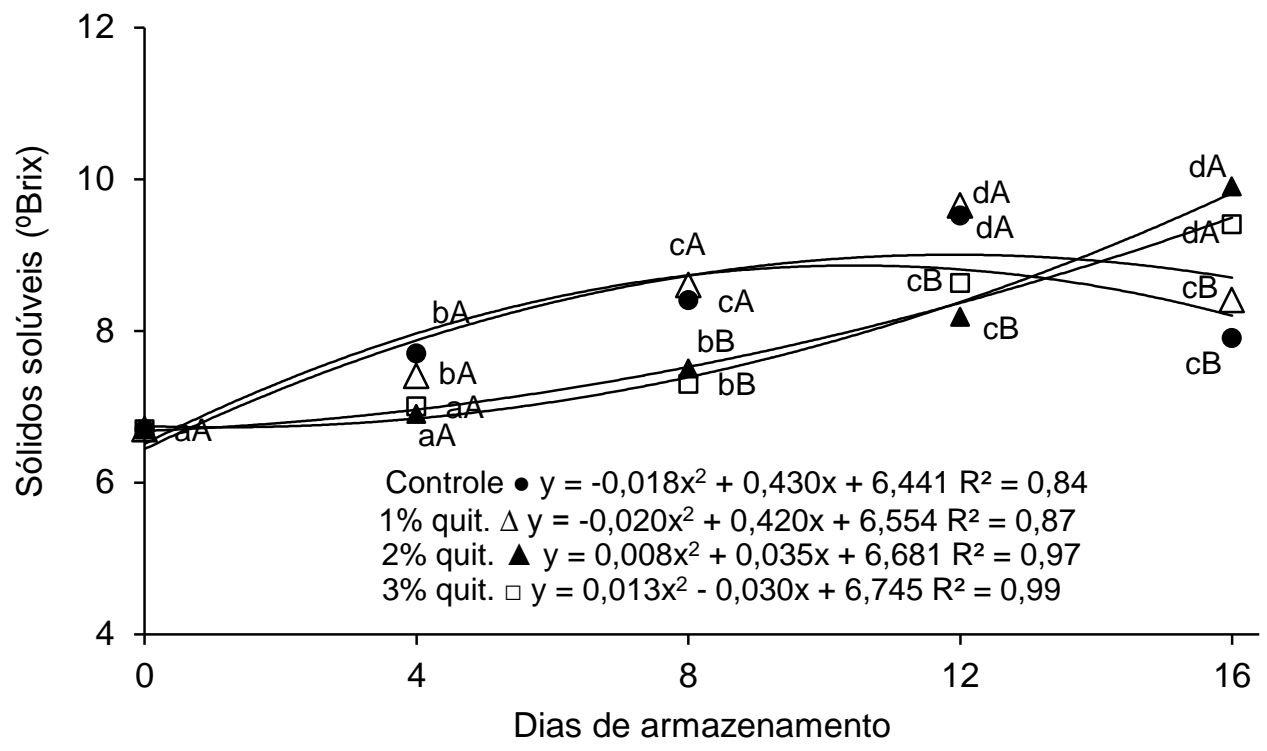

Essa redução nos SST observada no 12 은 dia nos tratamentos controle e $1 \%$ quitosana é um indicativo de perda de qualidade uma vez que os açucares tendem a serem utilizados como substrato no metabolismo respiratório. Por outro lado, nos frutos tratados com 2 e $3 \%$ o incremento nos SST até o 160 dia mostra a eficiência do revestimento em minimizar as trocas gasosas e, com isso, retardar a senescência como o consumo de açucares, por exemplo (Figura 5).

Resultados semelhantes foram observados por Souza et al. (2011), Gol et al. (2015) e Plácido et al. (2016) onde doses crescentes de quitosana ( 2 e $3 \%$ )preservaram o acúmulo de SST em mangas,carambolas e tangerinas armazenadas sob refrigeração, respectivamente.

No geral, os valores médios de SST encontrados nesse experimento $\left(6,7\right.$ a $\left.9,8^{\circ} \mathrm{Brix}\right)$ corroboram com os valores verificadospor Oliveira et al. (2010), que obtiveram valores médios de 5,3 a 9,2 ${ }^{\circ}$ Brix durante 0 armazenamento de carambolas com o uso de atmosfera modificada com filme plástico de PVC e polipropileno a $10 \stackrel{\circ}{ } \mathrm{C}$.

Os valores de acidez titulável (AT) na polpa dos frutos foram reduzindo à medida que houve o avanço no tempo de armazenamento (Figura 6). 
Figura 6. Acidez titulável (\% ácido oxálico.100 $\mathrm{g}^{-1} \cdot \mathrm{MF}$ ) em carambolas submetidas a diferentes concentrações de quitosana ao longo de 16 dias de armazenamento refrigerado a $10 \pm 2{ }^{\circ} \mathrm{C}$.

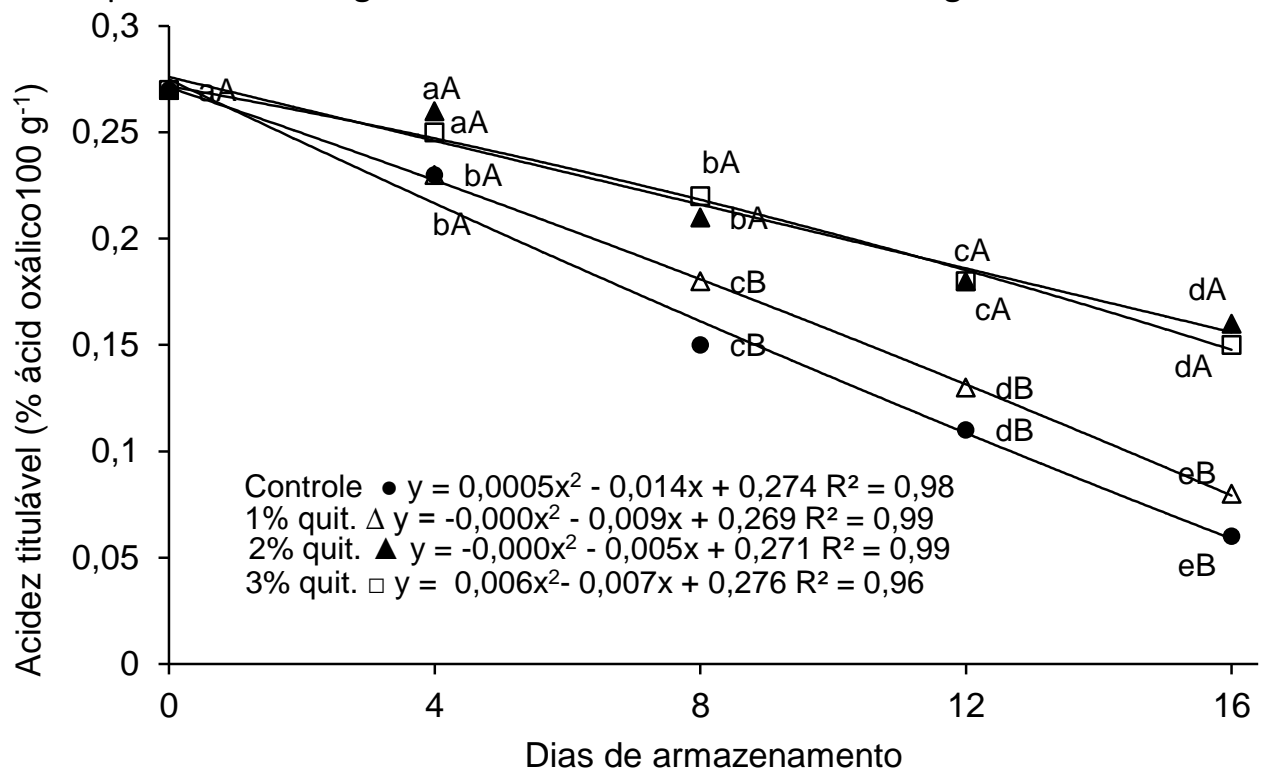

Nos frutos controle e naqueles revestidos com quitosana a $1 \%$ observou-se um decréscimo mais acentuado a partir do quarto dia de análise com teores abaixo de $0,10 \%$ ácido oxálico. $100 \mathrm{~g}^{-}$ ${ }^{1}$.MF ao 16 e dia de armazenamento. Nos frutos revestidos com quitosana a 2 e $3 \%$, os valores de AT decresceramem menor proporção não diferindo estatisticamente $(p<0,05)$ entre si observando teores superiores a 0,15\% ácido oxálico. $100 \mathrm{~g}^{-1} \mathrm{MF}$ aos 16 dias (Figura 6).

Chitarra e Chitarra (2005) explicam que a redução nos teores de acidez é um processo natural decorrente do consumo dos orgânicos sintetizados durante o amadurecimento como substrato energético (ATP) no metabolismo respiratório dos frutos visando manter sua vida útil. Tal fato reforça a eficiência da quitosana (2 e $3 \%)$ em preservar a degradação dos ácidos orgânicosna polpa das carambolas durante oarmazenamentorefrigerado (Figura 6).

Com relação ao índice de maturação (SST/AT), observam-sevalores crescentes com o tempo de armazenamento em todos os tratamentos (Figura 7).

Figura 7. Relação sólidos solúveis e acidez titulável (SS/AT) em carambolas submetidas a diferentes concentrações de quitosana ao longo de 16 dias de armazenamento refrigerado a $10 \pm 2{ }^{\circ} \mathrm{C}$.

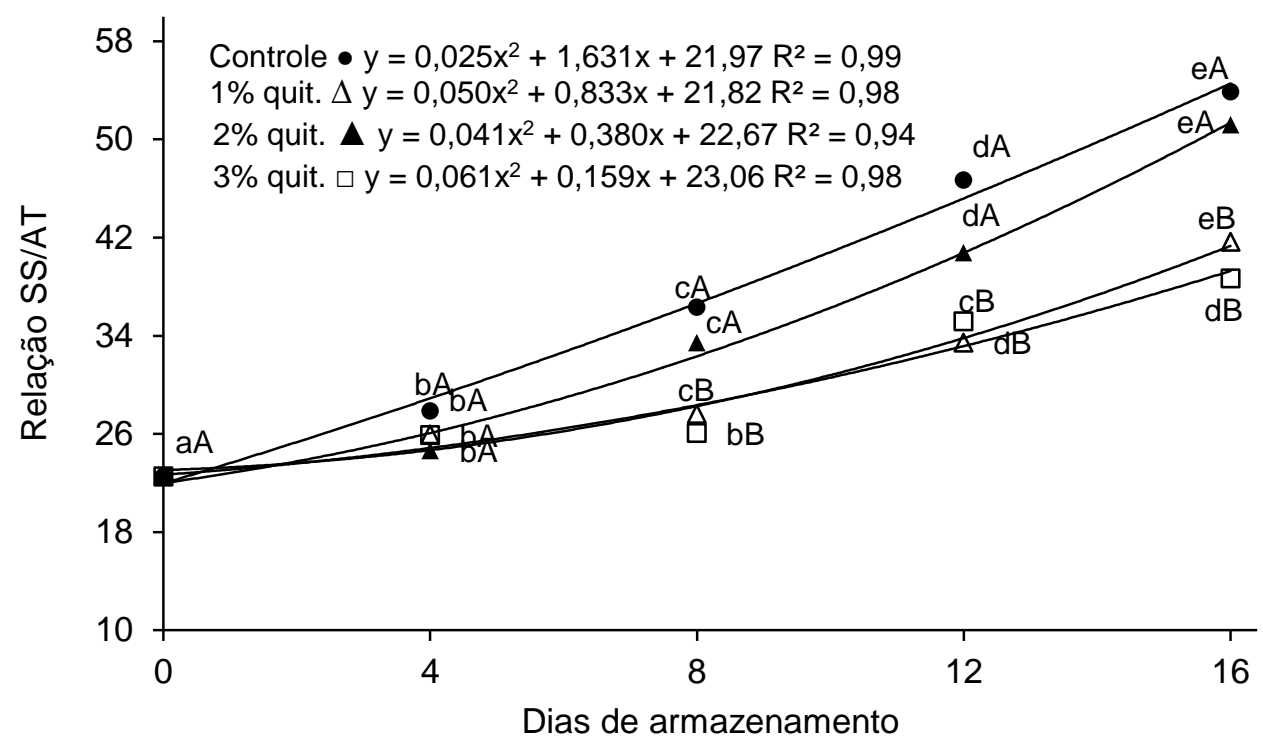


Em relação aos tratamentos, observa-se que nos frutos controle e quando revestidos com quitosana a $1 \%$, o acréscimo de SS/AT é significativamente maiores após o quarto dia de análise (Figura 7), observando valores médios superiores a 50,00 aos 16 dias. Esse aumento pode ser justificado pela maior perda de massa fresca observada nestes tratamentos, que passa a concentrar os SS na parede celular dos frutos.

A estabilidade observada na síntese de açucares (SS) e na degradação de ácidos orgânicos (AT) foi mais bem evidenciada nos frutos revestidos com 2 e $3 \%$ de quitosana durante o período de armazenamento (Figura 7), cujos valores médios ao 160 dia corresponderam a 41,63 e 38,65, respectivamente. Esses resultados sugerem carambolas com melhor relação de sabor e atraso no amadurecimento.
Esses resultados corroboram com 0 observado em outros frutos durante armazenamento refrigerado, tais como: tomates (COSTA et al., 2012), mamão (SOARES et al., 2015) e pêssegos, (GAYED et al., 2017) onde o revestimento de quitosana em variações de 1 a $3 \%$ possibilitaram um melhor balanço de SS e AT, com reflexo no atraso do amadurecimento e da manutenção do sabor dos frutos com o tempo de armazenamento.

No que se refere ao $\mathrm{pH}$, observasetendência de acréscimo com otempo de armazenamento (Figura 8). Esse aumento no $\mathrm{pH}$ decorre da redução na acidez titulável e caracteriza-se como um processo natural durante o armazenamento de frutos (CHITARRA; CHITARRA, 2005).

Figura 8. $\mathrm{pH}$ em carambolas submetidas a diferentes concentrações de quitosana ao longo de 16 dias de armazenamento refrigerado a $10 \pm 2{ }^{\circ} \mathrm{C}$.

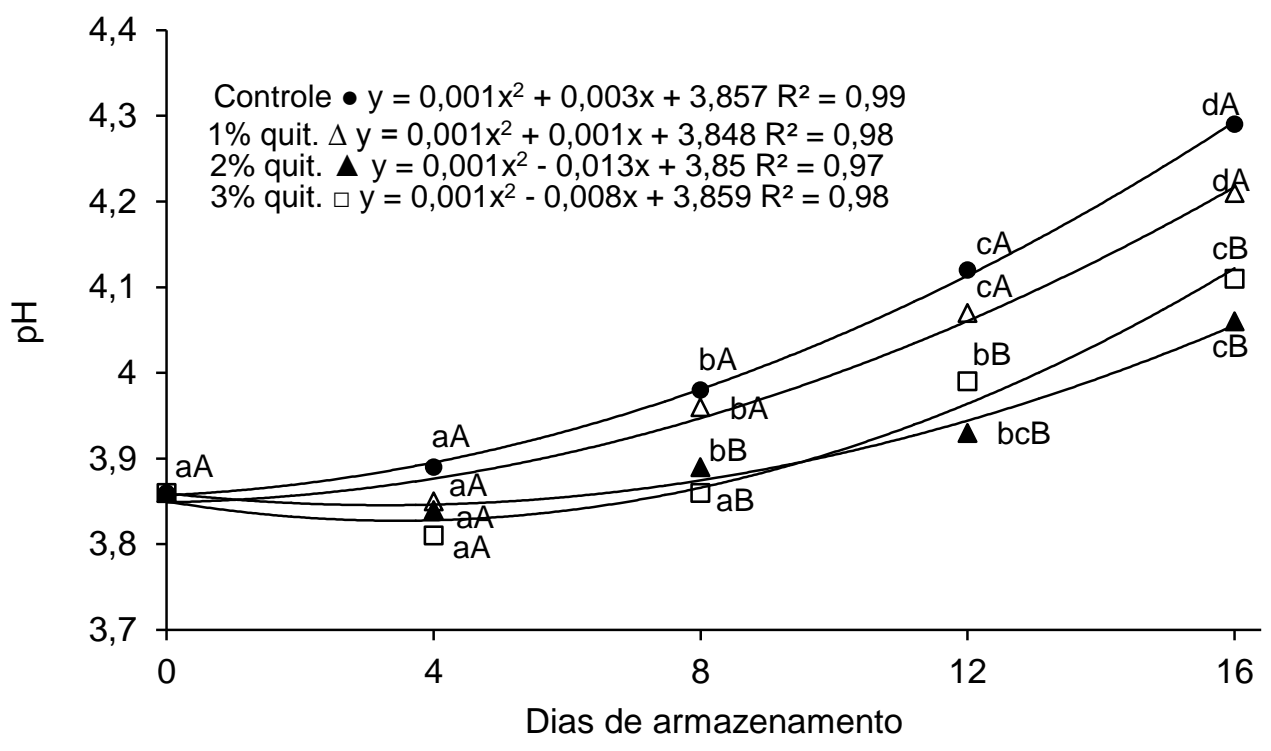

De maneira geral, o revestimento com quitosana não impediu o aumento do $\mathrm{pH}$ com o tempo de armazenamento, todavia os frutos revestidos com 2 e $3 \%$ de quitosana apresentaram valores mais baixos ao final de 16 dias $(4,06$ e $4,11 \mathrm{pH})$, respectivamente, se comparado ao tratamento controle $(4,29 \mathrm{pH})$ e com $1 \%$ de quitosana $(4,21 \mathrm{pH}$ ) (Figura 8$)$.

Esses baixos valores de $\mathrm{pH}$ nos frutos revestidos com 2 e $3 \%$ é uma característica interessante (Figura 8), pois se tratando da conservação pós-colheita, valores baixos de $\mathrm{pH}$ possibilitam maior período de armazenamento, uma vez que limitam o desenvolvimento de microorganismos (GONDIM et al., 2013).
A manutenção nos valores de $\mathrm{pH}$ também foi evidenciado por Rios e Bohórquez (2017) durante 14 dias de armazenamento à 5 oC de caquis tratados com $1 \%$ de quitosana. Por outro lado, as concentrações de quitosana: 0,25; 0,5, 1 e $2 \%$ não exerceram qualquer efeito sobre o $\mathrm{pH}$ de mangabas armazenadas a $3 \stackrel{\circ}{\mathrm{C}}$ por 15 dias (NASSER et al., 2016).

Houve redução no conteúdo de vitamina C com o tempo de armazenamento, independente do tratamento com quitosana com valores passando de 45,87 (dia zero) para 23,13 (16 dia) (Figura 9). 
Figura 9. Conteúdo de vitamina $\mathrm{C}\left(\mathrm{mg} \cdot 100 \mathrm{~g}^{-1} \mathrm{MF}\right)$ em carambolas submetidas a diferentes concentrações de quitosana ao longo de 16 dias de armazenamento refrigerado a $10 \pm 2{ }^{\circ} \mathrm{C}$.

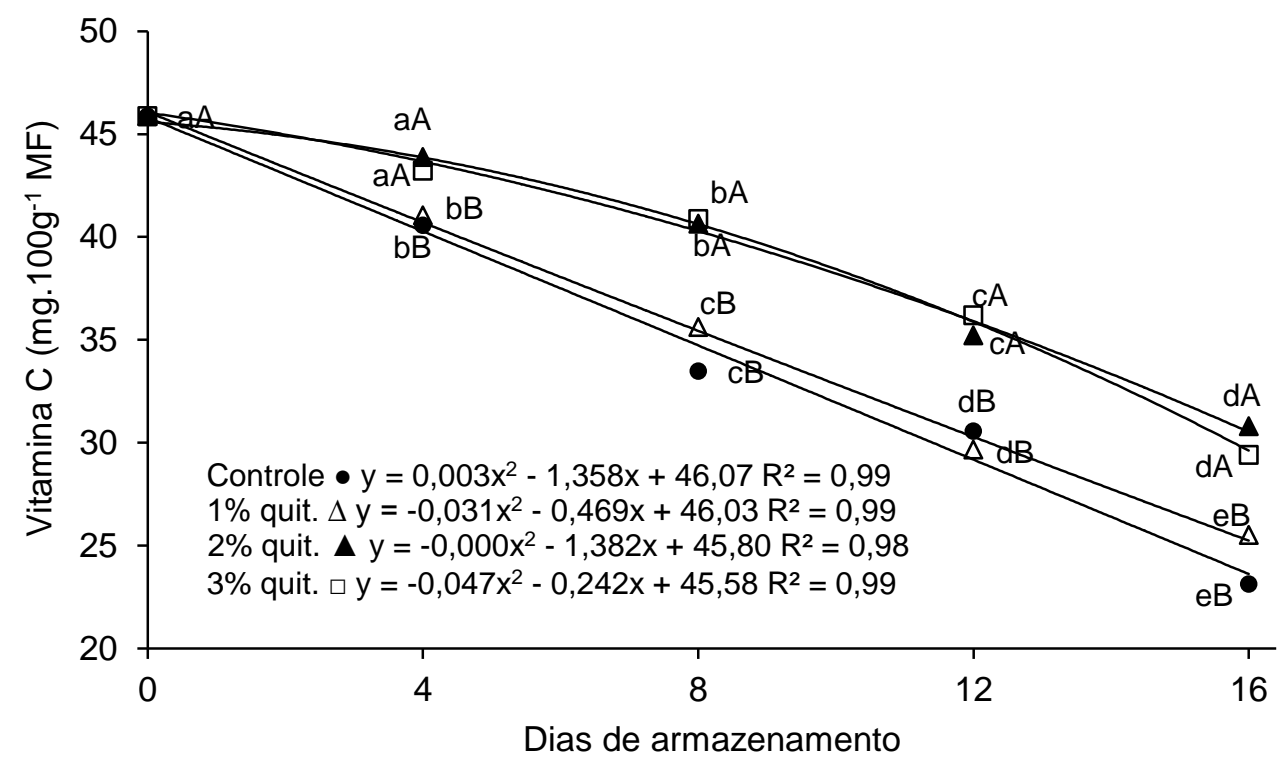

Em síntese, frutos revestidos com 2 e 3\% apresentaram redução em torno de $15,0 \mathrm{mg} .100$ $\mathrm{g}^{-1}$ entre o dia zero e o 16 - dia de avaliação em relação aos $22 \mathrm{mg} .100 \mathrm{~g}^{-1}$ observados nos frutos controle e quando revestidos com $1 \%$ de quitosana no mesmo período.

Esses resultados corroboram com o observado por Danget al. (2010) avaliando cerejas armazenadas a 4 으 durante 20 dias e Galo et al. (2014) em análise com mamão "Sunrise Solo', onde o' revestimento com quitosana ( 2 e 1,5\%, respectivamente) preservaram o conteúdo de vitamina $\mathrm{C}$ durante $\mathrm{o}$ armazenamento em relação ao controle.

Essa preservação na quantidade de vitamina Cpossivelmente está relacionada à permeabilidadedo revestimento de quitosana (2 e $3 \%$ ) ao vapor de água, retardando assim processos fisiológicos que levam a senescência como, por exemplo, a atividade de enzimas responsáveis pela oxidação do ácido ascórbico que atuam para minimizar estresse oxidativo celular.

\section{CONCLUSÕES}

O uso do revestimento de quitosanana pós-colheita da carambola mostrou-se eficiente em preservar a qualidade dos frutos por até 16 dias a $10 \stackrel{\circ}{\circ}$.

Concentrações de 2 e $3 \%$ resultaram em frutos mais firmes, com menor perda de massa, da coloração natural e do conteúdo de vitamina $C$ total, além de não promover alterações quanto ao sabor através do conteúdo de sólidos solúveis, acidez titulável e pH.

\section{REFERÊNCIAS}

ALI, A.; MUHAMMAD, M. T. M.; SIJAM, K.; SIDDIQUI, Y. Effect of chitosan coatings on the physicochemical characteristics of 'Eksotika II' papaya (Carica papaya L.) fruit during cold storage. Food Chemistry, Oxford, v.124, n.2, p.620-626, 2011. http://dx.doi.org/10.1016/j.foodchem.2010.06.0 855.

AOAC - Association of Official Analytical Chemistry. Official methods of analysis of the Association of Official Analytical Chemistry. Washington: AOAC, 2012.

BAUTISTA-BAÑOS, S.; HERNÁNDEZLAUZARDO, A. N.; VALLE, M. G. V.; HERNÁNDEZ-LÓPEZ, M.; BARKA, E. A.; BOSQUEZ-MOLINA, E.; WILSON C. L. Chitosan as a potential natural compound to control pre and postharvest diseases of horticultural commodities. Crop Protection, London, v. 25, p.108-118, 2006. http://dx.doi.org/10.1016/i.cropro.2005.03.0100.

BERGER, L.; STAMFORD, T.; STAMFORD, N. Perspectivas para o uso da quitosana na agricultura. Revista Iberoamericana de Polímeros, v.12, n.4, p. 195-215, 2011.

CERQUEIRA, T. S.; JACOMINO, A. P.; SASAKI, F. F.; ALLEONI, A. C. C. Recobrimento de goiabas com 
filmes protéicos e de quitosana. Bragantia, Campinas, v. 70, n. 1, p. 216-221, 2011. http://dx.doi.org/10.1590/S000687052011000100028.

CHEN, J.; WANG, X. experimental instruction of plant physiology. South Chima University of Tecnology Press, Guangzhou, p. 124, 2002.

CHITARRA, A. B.; CHITARRA, M. I. F. Pós-colheita de frutos e hortaliças: fisiologia e manuseio. 2. ed. Lavras: UFLA, 2005.

DANG, Q. F.; YAN, J. Q.; LI, Y.; CHENG, X. J.; LIU, C. S.; CHEN, X. G. Chitosan acetate as an active coating Material and Its Effects on the Storing of Prunusavium L. Journal of Food Science, Qingdao, CHN, v. 75, n. 2, 2010. http://dx.doi.org/10.1111/i.1750-

3841.2009.01483x.

DING, P.; AHMAD, S. H.; GHAZALI, H. M. Changes in select quality characteristics of minimally process carambola (Averrhoa carambola L.) when treated with ascorbic acid. Journal of the Science of Food and Agriculture, Barking, v. 87, p. 702709, 2007. http://dx.doi.org/10.1002/isfa.2772.

DONADIO, L. C.; SILVA, J. A. A.; ARAÚJO, P. S. R.; PRADO, R. M. Caramboleira (Averrhoa carambola L.) Revista Brasileira de Fruticultura, Jaboticabal, SP, v.33, n.4, p.1300-1307, 2001.

FREDDO, A. R.; MAZARO, S. M.; BRUN, E. J.; JUNIOR, A. W. Quitosana como fungistático no crescimento micelial de Rhizoctonia solani Kuhn. Ciência Rural, Santa Maria, RS, v.44, n.1, p.1-4, $2014 . \quad$ http://dx.doi.org/10.1590/S010384782014000100001 .

GALO, J. Q. B.; SOUZA, M. L.; KUSDRA, J. F.; MATTIUZ, C. F. M. Conservação pós-colheita de mamão 'Sunrise solo' com uso de quitosana. Revista Brasileira de Fruticultura, v. 36, n. 2, p.305-312, $2014 . \quad$ DOI: http://dx.doi.org/10.1590/0100-2945-194/13.

GAYED, A. A. N. A.; SHAARAWI, S. A. M. A.; ELKHISHEN, M. A.; ELSHERBINI, N. R. M. Preharvest application of calcium chloride and chitosan on fruit qualityand storability of 'Early Swelling' peach during cold storage. Ciência e Agrotecnologia, v. 41, n. 2, p. 220-231, 2017. http://dx.doi.org/10.1590/1413$\underline{70542017412005917}$

GOL, N. B.; CHAUDHARI, M. L.; RAO, T. R. Effect of edible coatings on quality and shelf life of carambola (Averrhoa carambola L.) fruit during storage.Journal of food science and technology, v. $52, \quad$ n. $1, \quad$ p. $78-91,2015$. DOI:http://dx.doi.org/10.1007/s13197-013-0988$\underline{9 .}$

HOJO, E. T. D.; DURIGAN, J. F.; HOJO, R. H. Uso de embalagens plásticas e cobertura de quitosana na conservação pós-colheita de lichias. Revista Brasileira de Fruticultura, v. 33, n.1 p.377-383, 2011. DOI: http://dx.doi.org/10.1590/S010029452011000500048.

HOSSAIN, M. S.; IQBAL, A.Effect of shrimp chitosan coating on postharvest quality of banana (Musa sapientum L.) fruits. International Food Research Journal, v. 23, n. 1, p. 277-283, 2016.

MARIANO-NASSER, F. C.; BOLIANI, A. C.; NASSER, M. D.; PAGLIARINI, M. K.; MENDONÇA, V. Z. Conservação de mangabas submetidas à aplicação de quitosana. Revista Científica, v.44, n.3, p.279-285, 2016. http://dx.doi.org/10.15361/1984-

5529.2016v44n3p279-285.

NATALE, W.; PRADO, R. M.; ROZANE, D. E.; ROMUALDO, L. M.; SOUZA, H. A. DE; HERNANDES, A. Resposta da caramboleira à calagem. Revista Brasileira de Fruticultura, Jaboticabal, SP, v.30 n.4, p. 1136-1145, 2008. http://dx.doi.org/10.1590/S010029452008000400048.

NEVES, L. C.; BENDER, R. J.; ROMBALDI, C. V.; VIEITES, R. L. Qualidade de carambolas azedas cV. 'Golden Star' tratadas com $\mathrm{CaCl}_{2}$ por imersão e armazenadas sob refrigeração. Revista Brasileira de Fruticultura, v.26, n.1, p.102- 123, 2004. http://dx.doi.org/10.1590/S010029452004000100010 .

NUNES, J. S.; CASTRO, D.; GOMES, J. P.; SOUSA, F. C. Vida útil pós-colheita de carambolas submetidas a diferentes tratamentos. Gaia scientia, João Pessoa, PB, v. 9, n. 1, p. 119-123, 2015. http://dx.doi.org/10.21707/gs.v9i1.18128 
OLIVEIRA, L. F. G.; SANTOS, P. N.; CANA, E.; JUNIOR, J. L.; RODRIGUES, S. Utilização da atmosfera modificada na conservação pósColheita de carambola. Global Science. Technology, v. 3, n. 2, p. 49-59, 2010.

OLIVEIRA, T. A.; AROUCHA, E. M. M.; LEITE, R. H. L.; FERREIRA, R. M. A.; SANTOS, F. K. G. Conservação pós-colheita de carambola sob refrigeração com recobrimento de biofilme de gelatina e PVC. Revista Verde, v 10, n.4, p.59-66, 2015.

http://dx.doi.org/10.18378/rvads.v10i4.3653

RIOS, A.; BOHÓRQUEZ, N. V. Effect of chitosan coatings on the quality of persimmon under commercial storage conditions. Brazilian Journal of Food Research, v. 8, n. 1, p. 91-104, 2017.

SEPIAH-PLOETZ, R. C.; COOKE, A. W. Disease of carambola. In: PLOETZ, R. C. Disease of tropical fruit crops. Washington, $D C$ : $C A B$ International, 2003. p. 145-155.

SHUI, G.; LEONG, L. P. Residue from starfruit as valuable source for functional food ingradients and antioxidant neutraceuticals. Food Chemistry, v.97, n.2, p.277-284, 2006. http://dx.doi.org/10.1016/j.foodchem.2005.03.0 $\underline{488}$.

SILVA, F. A. S.; AZEVEDO, C. A. V. The Assistat Software Version 7.7 and its use in the analysis of experimental data. African Journal Agricola Research, v.11, n.39, p.3733-3740, 2016. http://dx.doi.org/10.5897/AJAR2016.11522

SOARES, L. G.; SILVA, S. M.; PEREIRA, V. C. S.; BRITO, A. L.; RODRIGUES, T. L. Qualidade durante o armazenamento de mamão 'Golden' recobertos com biofilmes a base de quitosana. In: Congresso Brasileiro de Processamento mínimo e Pós-colheita de frutas, flores e hortaliças, 001. Anais... Aracaju-SE, 2015.

SOUZA, M. L.; MORGADO, C. M. A.; MARQUES, K. M.; MATTIUZ, C. F. M.; MATTIUZ, B. Pós-colheita de mangas 'Tommy Atkins' recobertas com quitosana. Revista Brasileira de Fruticultura, Jaboticabal, SP, v. especial, p. 337-343, 2011. http://dx.doi.org/10.1590/S010029452011000500042.
TEIXEIRA, G. H. A.; DURIGAN, J. F.; ALVES, T. E. Qualidade de frutos de carambola após tratamento térmico. Brazilian Journal Food Technology, .10, p. 43- 50, 2007.

Recebido para publicação em 30/04/2017

Revisado em 22/03/2018

Aceito em 26/06/2018 